\title{
Association of Smartphone Ownership and Internet Use With Markers of Health Literacy and Access: Cross-sectional Survey Study of Perspectives From Project PLACE (Population Level Approaches to Cancer Elimination)
}

Sachiko M Oshima ${ }^{1 *}$, BA; Sarah D Tait ${ }^{*}$, BA; Samantha M Thomas ${ }^{2,3}$, MS; Oluwadamilola M Fayanju ${ }^{3,4}$, MA, MD, MPHS; Kearston Ingraham ${ }^{3}$, MPH; Nadine J Barrett ${ }^{3,5,6}$, MA, MS, PhD; E Shelley Hwang ${ }^{3,4}$, MPH, MD

${ }^{1}$ Duke University School of Medicine, Durham, NC, United States

${ }^{2}$ Department of Biostatistics \& Bioinformatics, Duke University School of Medicine, Durham, NC, United States

${ }^{3}$ Duke Cancer Institute, Durham, NC, United States

${ }^{4}$ Department of Surgery, Duke University School of Medicine, Durham, NC, United States

${ }^{5}$ Department of Family Medicine and Community Health, Duke University School of Medicine, Durham, NC, United States

${ }^{6}$ Duke Clinical Translation Science Institute, Duke University School of Medicine, Durham, NC, United States

*these authors contributed equally

Corresponding Author:

E Shelley Hwang, MPH, MD

Department of Surgery

Duke University School of Medicine

465 Seeley Mudd Building

Durham, NC, 27710

United States

Phone: 19196846849

Email: shelley.hwang@duke.edu

\begin{abstract}
Background: Telehealth is an increasingly important component of health care delivery in response to the COVID-19 pandemic. However, well-documented disparities persist in the use of digital technologies.

Objective: This study aims to describe smartphone and internet use within a diverse sample, to assess the association of smartphone and internet use with markers of health literacy and health access, and to identify the mediating factors in these relationships.

Methods: Surveys were distributed to a targeted sample designed to oversample historically underserved communities from April 2017 to December 2017. Multivariate logistic regression was used to estimate the association of internet and smartphone use with outcomes describing health care access and markers of health literacy for the total cohort and after stratifying by personal history of cancer. Health care access was captured using multiple variables, including the ability to obtain medical care when needed. Markers of health literacy included self-reported confidence in obtaining health information.
\end{abstract}

Results: Of the 2149 participants, 1319 (61.38\%) were women, 655 (30.48\%) were non-Hispanic White, and 666 (30.99\%) were non-Hispanic Black. The median age was 51 years (IQR 38-65). Most respondents reported using the internet (1921/2149, $89.39 \%)$ and owning a smartphone $(1800 / 2149,83.76 \%)$. Compared with the respondents with smartphone or internet access, those without smartphone or internet access were more likely to report that a doctor was their most recent source of health information $(344 / 1800,19.11 \%$ vs $116 / 349,33.2 \%$ for smartphone and 380/1921, 19.78\% vs 80/228, 35.1\% for internet, respectively; both $P<.001)$. Internet use was associated with having looked for information on health topics from any source (odds ratio [OR] 3.81, 95\% CI 2.53-5.75) and confidence in obtaining health information when needed (OR 1.83 , 95\% CI 1.00-3.34) compared with noninternet users. Smartphone owners had lower odds of being unable to obtain needed medical care (OR 0.62, 95\% CI 0.40-0.95) than nonsmartphone owners. Among participants with a prior history of cancer, smartphone ownership was significantly associated with higher odds of confidence in ability to obtain needed health information (OR 5.63, 
95\% CI 1.05-30.23) and lower odds of inability to obtain needed medical care (OR 0.17, 95\% CI 0.06-0.47), although these associations were not significant among participants without a prior history of cancer.

Conclusions: We describe widespread use of digital technologies in a community-based cohort, although disparities persist. In this cohort, smartphone ownership was significantly associated with ability to obtain needed medical care, suggesting that the use of smartphone technology may play a role in increasing health care access. Similarly, major illnesses such as cancer have the potential to amplify health engagement. Finally, special emphasis must be placed on reaching patient populations with limited digital access, so these patients are not further disadvantaged in the new age of telehealth.

(J Med Internet Res 2021;23(6):e24947) doi: 10.2196/24947

\section{KEYWORDS}

telehealth; technology; health literacy; access to health care; mobile phone

\section{Introduction}

\section{Background}

The COVID-19 pandemic has highlighted the increasing dependence of the health system on telemedicine because providers have relied on telehealth to provide patient care while minimizing the risk of viral transmission [1-3]. Telehealth, or the use of technology-including the internet and mobile phones - to enable or improve health or health care [4,5], has expanded in scope and capabilities in recent decades. Patients can now access personal health information through patient portals [6], look up health information independently without professional medical guidance [7-11], and provide feedback to other consumers on their experiences with certain hospitals or providers through these media [12]. Studies have shown that the use of technology in the health sector can improve intervention efficacy, patient satisfaction, and, ultimately, clinical outcomes [13-17]. Technology has assumed a growing role within the health care landscape, with more than $60 \%$ of all US health care institutions using at least one form of telehealth [18], with some engaging in more telehealth visits than in-person visits [19].

Although telehealth has shown promise as a means to expand access to care [20,21], documented disparities persist among individuals who engage with health technology. The gap in access to technology based on social, physical, and societal factors is often referred to as the digital divide [22]. Previous work has characterized this divide extensively, with older, less-educated individuals having lower use of internet, mobile phone, and smartphone technologies [23-25] and preferring to receive health information through printed media compared with younger and more-educated individuals [26]. Furthermore, bridging the divide involves not only addressing gaps in physical access to technology, known as the first digital divide, but also the reliability of access and technological literacy, known as the second digital divide [27-30].

The second digital divide reflects the well-documented association between lower rates of phone and internet use with decreased health literacy [31-33]. This relationship seems to be multifaceted, with recent studies demonstrating an association not only between health literacy and the likelihood of technology adoption, but also between health literacy and the use of health information technology $[34,35]$. These findings allude to the evolving body of literature characterizing the relationship between digital technology and health outcomes. Preliminary studies have demonstrated that increased internet use can positively affect perceived health outcomes as well as the use of health care services. These differences in the outcomes, benefits, and impacts of technology use represent the third digital divide $[30,36]$. Work thus far describing the relationship between health literacy and health outcomes has led to mixed, inconclusive results [37].

A better understanding of the nature and ramifications of the digital divide is critical because patient populations who are already disadvantaged are at increased risk of being marginalized as the health system evolves to increasingly rely on telehealth to deliver care. Studies have already been published describing the widening inequity resulting from the health system's increased reliance on telehealth as a result of the COVID-19 pandemic and the negative repercussions that most frequently and meaningfully affect vulnerable communities [38]. Furthermore, given the United States' ongoing poor performance in health care access and affordability compared with peer developed nations [39], the US health care system is particularly vulnerable to widening disparities as a result of the stress of dealing with the COVID-19 pandemic.

\section{Objective}

This study seeks to provide valuable data from a racially diverse cohort of North Carolina residents to further characterize the current state of digital technology use and to explore the relationship among technological access, health literacy, and health care access. Furthermore, this study builds on preliminary research assessing how major illnesses such as cancer relate to internet- and smartphone-use behaviors and their associations with markers of health literacy and health care access [40,41].

\section{Methods}

\section{Study Design and Participants}

This cross-sectional study used survey data derived from a community health assessment initiative, Project PLACE (Population Level Approaches to Cancer Elimination). The survey was administered to a targeted convenience sample of diverse populations across a predefined patient catchment area in proximity to a National Cancer Institute-designated comprehensive cancer center in North Carolina, and it aimed to oversample historically underserved communities [42]. Data were collected from April 2017 to December 2017. The study 
protocol was approved by the Duke University Institutional Review Board (\#00062661).

Most of the participants were recruited from community organizations located in Durham, Wake, Vance, Alamance, and Johnston counties in central North Carolina. Community navigators worked in conjunction with 24 community partners to collect survey data using a multimodal approach. The community partners-comprising community organizations, faith organizations, community outreach programs, and a health clinic-distributed the surveys to their constituents at 47 different community events. Community partners received stipends (US \$10 per survey, up to US \$2000) for their collaboration. Survey participants were offered items valued at US \$5 or less (eg, water bottle and tote bag) for their participation [43].

\section{Survey Design}

The 91-item, self-administered survey was available in English, Spanish, and Chinese and could be completed on paper or on the web. The survey items included a combination of program-specific and pre-existing validated measures sourced from national surveys, including the Health Information National Trend Survey and the National Health Interview Study [44]. Data from select survey items that assessed sociodemographic factors, personal cancer history, patterns of mobile phone and internet use, and markers of health literacy and health care access were used in this study (Multimedia Appendix 1). The place of residence, metropolitan or nonmetropolitan, was captured with self-reported ZIP code that was coded using Rural-Urban Continuum Codes (RUCC) in which RUCC 1 to 3 were coded as metropolitan and RUCC 4 to 9 were coded as nonmetropolitan $[45,46]$.

\section{Independent Variables}

The primary independent variables included internet use and smartphone ownership. Internet use was captured with this question: "Do you ever go on-line to access the Internet or World Wide Web, or to send and receive e-mail?" Smartphone ownership was captured with this question: "Do you currently have a Smart phone such as an iPhone, Android, Blackberry or Windows phone?"

\section{Outcome Measures}

The primary outcome measures were health care access and markers of health literacy. Health care access was captured with several items, including having a usual place of care when sick or in need of advice regarding health, the type of place attended for care, being unable to get care when needed, health insurance status, and participation in medical research. Markers of health literacy were captured with several additional items, including having looked for information on health topics, the source used for information on health topics, self-reported confidence in the ability to obtain health information, and self-reported understanding of numerical information (ie, numeracy). The variable "self-reported numeracy" was dichotomized by grouping survey responses 1-3 as "low self-reported numeracy" and survey responses 4-6 as "high self-reported numeracy." The variable "confidence in ability to obtain health information if needed" was dichotomized with the survey responses "completely confident," "very confident," and "somewhat confident" grouped together compared with the grouping of "a little confident" and "not at all confident" (Multimedia Appendix 1).

\section{Statistical Analysis}

Descriptive statistics were used to summarize the study sample. Continuous and categorical variables were summarized as median (IQR), where IQR is reported as first quartile value-third quartile value, and n (\%), respectively, by smartphone ownership and internet use. Differences were tested using the chi-square test or Fisher exact test for categorical variables, as appropriate, and the two-tailed $t$ test for continuous variables.

Logistic regression was used to estimate the association of smartphone ownership and internet use, respectively, with health care use and literacy variables after adjustment for sociodemographic factors both in the total study cohort and after stratifying by personal history of cancer. Covariates were selected based on univariate analysis $(P<.10)$. Only respondents with complete data were included in each analysis, and effective sample sizes are indicated for each table and figure. No adjustments were made for multiple comparisons. Two-tailed tests were used for all analyses, and the threshold for significance was set at $P<.05$. All statistical analyses were conducted using SAS version 9.4 (SAS Institute).

\section{Results}

\section{Participant Sociodemographic and Digital Technology Use Characteristics}

A total of 2315 surveys were completed. Of these 2315 surveys, $2149(92.83 \%)$ respondents answered all 3 questions pertaining to mobile phone ownership, smartphone ownership, and internet use. Demographic, personal health history, and smartphone and internet use characteristics are shown in Table 1. 
Table 1. Baseline characteristics of study cohort $(\mathrm{N}=2149)^{\mathrm{a}}$.

\begin{tabular}{|c|c|c|c|c|c|c|c|c|c|}
\hline \multirow[t]{2}{*}{ Characteristics } & \multirow[t]{2}{*}{ All respondents } & \multicolumn{4}{|c|}{ Smartphone ownership } & \multicolumn{4}{|l|}{ Internet use } \\
\hline & & $\begin{array}{l}\text { No } \\
(\mathrm{n}=349), \mathrm{n} \\
(\%)\end{array}$ & $\begin{array}{l}\text { Yes }(\mathrm{n}=1800), \\
\mathrm{n}(\%)\end{array}$ & $P$ value & $\begin{array}{l}\text { Chi- } \\
\text { square } \\
(d f)\end{array}$ & $\begin{array}{l}\text { No } \\
(\mathrm{n}=228), \mathrm{n} \\
(\%)\end{array}$ & $\begin{array}{l}\text { Yes }(\mathrm{n}=1921), \\
\mathrm{n}(\%)\end{array}$ & $P$ value & $\begin{array}{l}\text { Chi- } \\
\text { square } \\
(d f)\end{array}$ \\
\hline Age, median (IQR) & $51(38-65)$ & $68(58-76)$ & $48(36-61)$ & $<.001$ & $272.3(1)$ & $67(55-76)$ & $49(37-63)$ & $<.001$ & $130.1(1)$ \\
\hline Gender, n (\%) & & & & .32 & $\mathrm{~N} / \mathrm{A}^{\mathrm{b}}$ & & & $.99^{\mathrm{c}}$ & N/A \\
\hline Female & $1319(61.38)$ & $216(16.4)$ & $1103(83.62)$ & & & $133(10.1)$ & $1186(89.92)$ & & \\
\hline Male & $732(34.06)$ & $106(14.5)$ & $626(85.52)$ & & & $74(10.1)$ & $658(89.89)$ & & \\
\hline Other & $8(0.37)$ & $0(0)$ & $8(100)$ & & & $0(0)$ & $8(100)$ & & \\
\hline \multicolumn{2}{|l|}{ Race and ethnicity, n (\%) } & & & .001 & $19.1(4)$ & & & .94 & $0.8(4)$ \\
\hline Hispanic & $300(13.96)$ & $52(17.3)$ & $248(82.67)$ & & & $29(9.7)$ & $271(90.33)$ & & \\
\hline Non-Hispanic Asian & $202(9.4)$ & $17(8.4)$ & $185(91.58)$ & & & $19(9.4)$ & $183(90.59)$ & & \\
\hline Non-Hispanic Black & $666(30.99)$ & $78(11.7)$ & $588(88.29)$ & & & $64(9.6)$ & $602(90.39)$ & & \\
\hline Non-Hispanic White & $655(30.48)$ & $118(18)$ & $537(81.98)$ & & & $55(8.4)$ & $600(91.6)$ & & \\
\hline Other & $82(3.82)$ & $10(12.2)$ & $72(87.8)$ & & & $8(9.8)$ & $74(90.24)$ & & \\
\hline \multicolumn{2}{|l|}{ Income adequacy, n (\%) } & & & .02 & $5.8(1)$ & & & .27 & $1.2(1)$ \\
\hline $\begin{array}{l}\text { Living comfortably or } \\
\text { getting by on present } \\
\text { income }\end{array}$ & $1629(75.8)$ & $234(14.4)$ & $1395(85.64)$ & & & $156(9.6)$ & $1473(90.42)$ & & \\
\hline $\begin{array}{l}\text { Finding it difficult or } \\
\text { very difficult on } \\
\text { present income }\end{array}$ & $366(17.03)$ & $71(19.4)$ & $295(80.6)$ & & & $42(11.5)$ & $324(88.52)$ & & \\
\hline \multicolumn{2}{|l|}{ Education level, n (\%) } & & & $<.001$ & $138.1(2)$ & & & $<.001$ & $140.6(2)$ \\
\hline High school or less & $487(22.66)$ & $151(31)$ & $336(68.99)$ & & & $114(23.4)$ & $373(76.59)$ & & \\
\hline $\begin{array}{l}\text { Post high school } \\
\text { training or some col- } \\
\text { lege }\end{array}$ & $535(24.9)$ & $84(15.7)$ & $451(84.3)$ & & & $48(8.97)$ & 487 (91.03) & & \\
\hline $\begin{array}{l}\text { College graduate or } \\
\text { higher }\end{array}$ & $1017(47.32)$ & $78(7.7)$ & $939(92.33)$ & & & $40(3.9)$ & $977(96.07)$ & & \\
\hline \multicolumn{2}{|c|}{ Occupational status, $\mathrm{n}(\%)$} & & & $<.001$ & $251.5(4)$ & & & $<.001$ & $100.6(4)$ \\
\hline Disabled & $83(3.86)$ & $30(36.1)$ & $53(63.86)$ & & & $19(22.9)$ & $64(77.11)$ & & \\
\hline Employed & $1192(55.47)$ & $77(6.5)$ & $1115(93.54)$ & & & $66(5.5)$ & $1126(94.46)$ & & \\
\hline Unemployed & $89(4.14)$ & $18(20.2)$ & $71(79.78)$ & & & $5(5.6)$ & $84(94.38)$ & & \\
\hline Retired & $456(21.22)$ & $163(35.7)$ & $293(64.25)$ & & & $93(20.4)$ & $363(79.61)$ & & \\
\hline Other & $190(8.84)$ & $20(10.5)$ & $170(89.47)$ & & & $15(7.9)$ & $175(92.11)$ & & \\
\hline \multicolumn{2}{|l|}{ Insurance status, n (\%) } & & & $<.001$ & $196.3(3)$ & & & $<.001$ & $70.7(3)$ \\
\hline Private & $1048(48.77)$ & $56(5.3)$ & $992(94.66)$ & & & $51(4.9)$ & $997(95.13)$ & & \\
\hline Public & $626(29.13)$ & $192(30.7)$ & $434(69.33)$ & & & $108(17.3)$ & $518(82.75)$ & & \\
\hline $\begin{array}{l}\text { Insured, unknown } \\
\text { type }\end{array}$ & $95(4.42)$ & $18(18.9)$ & $77(81.05)$ & & & $14(14.7)$ & $81(85.26)$ & & \\
\hline None & $266(12.38)$ & $44(16.5)$ & $222(83.46)$ & & & $27(10.2)$ & $239(89.85)$ & & \\
\hline \multicolumn{2}{|l|}{ Location type, n (\%) } & & & $<.001$ & $39.1(1)$ & & & $<.001$ & $24.4(1)$ \\
\hline Metropolitan & $1696(78.92)$ & $222(13.1)$ & $1474(86.91)$ & & & $143(8.4)$ & $1553(91.57)$ & & \\
\hline Nonmetropolitan & $373(17.36)$ & $97(26)$ & $276(73.99)$ & & & $63(16.9)$ & $310(83.11)$ & & \\
\hline \multicolumn{3}{|c|}{ Personal history of cancer, $\mathrm{n}(\%)$} & & $<.001$ & $35.8(1)$ & & & .07 & $3.3(1)$ \\
\hline No & $1761(81.95)$ & $247(14)$ & $1514(85.97)$ & & & $175(9.9)$ & $1586(90.06)$ & & \\
\hline
\end{tabular}




\begin{tabular}{|c|c|c|c|c|c|c|c|c|}
\hline \multirow[t]{2}{*}{ Characteristics } & \multirow[t]{2}{*}{ All respondents } & \multicolumn{4}{|c|}{ Smartphone ownership } & \multicolumn{3}{|l|}{ Internet use } \\
\hline & & $\begin{array}{l}\text { No } \\
(\mathrm{n}=349), \mathrm{n} \\
(\%)\end{array}$ & $\begin{array}{l}\text { Yes }(\mathrm{n}=1800) \\
\mathrm{n}(\%)\end{array}$ & $P$ value & $\begin{array}{l}\text { Chi- } \\
\text { square } \\
(d f)\end{array}$ & $\begin{array}{l}\text { No } \\
(\mathrm{n}=228), \mathrm{n} \\
(\%)\end{array}$ & $\begin{array}{l}\text { Yes }(\mathrm{n}=1921), \quad P \text { value } \\
\mathrm{n}(\%)\end{array}$ & $\begin{array}{l}\text { Chi- } \\
\text { square } \\
(d f)\end{array}$ \\
\hline Yes & $340(15.82)$ & $92(27.1)$ & $248(72.94)$ & & & $45(13.2)$ & $295(86.76)$ & \\
\hline
\end{tabular}

\footnotetext{
${ }^{\mathrm{a}}$ Test statistics and $d f$ are presented for the chi-square and $t$ test $P$ values only.

${ }^{\mathrm{b}} \mathrm{N} / \mathrm{A}$ : not applicable.

${ }^{\mathrm{c}}$ Fisher exact test $P$ value.
}

The median age was 51 years (IQR 38-65), and most of the participants were women $(1319 / 2149,61.38 \%)$. The racial and ethnic distribution was $13.96 \%$ (300/2149) Hispanic, 9.4\% (202/2149) non-Hispanic Asian, 30.99\% (666/2149) non-Hispanic Black, 30.48\% (655/2149) non-Hispanic White, and $3.82 \%$ (82/2149) other, whereas $11.35 \%$ (244/2149) chose not to respond to this question. Overall, $75.8 \%$ (1629/2149) of the participants reported living comfortably or getting by on their present income, and $47.32 \%$ (1017/2149) reported an education level of college graduate or higher. Most of the participants lived in a metropolitan area (1696/2149, 78.92\%), were employed $(1192 / 2149,55.47 \%)$, and did not have a history of cancer $(1761 / 2149,81.95 \%)$. In total, $89.39 \%$ (1921/2149) of the respondents reported using the internet, $96.32 \%$ (2070/2149) reported owning a mobile phone, and $83.76 \%$ (1800/2149) reported owning a smartphone (Figure 1).

Figure 1. Prevalence of smartphone ownership and internet use among study cohort.

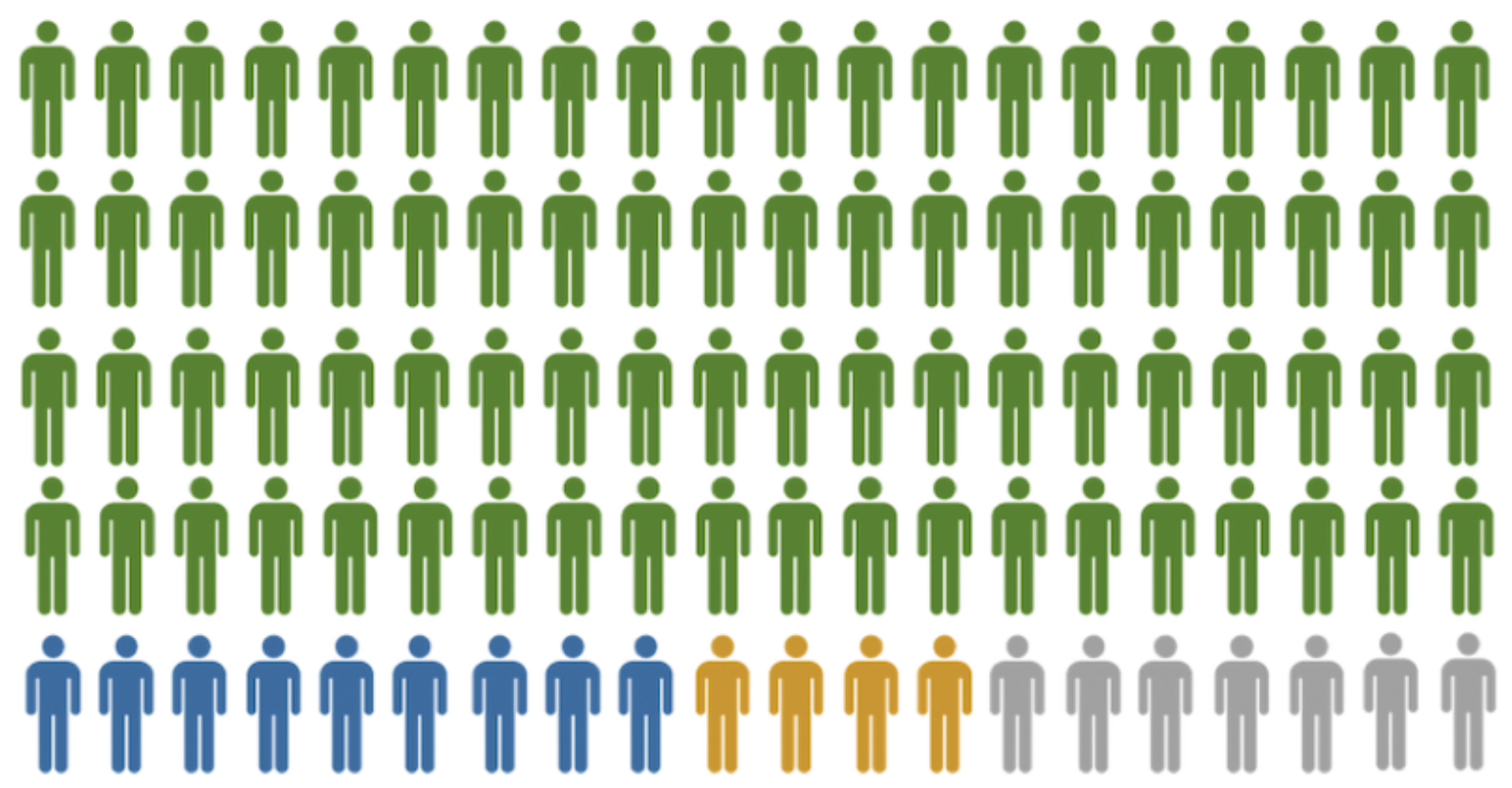

Owns smartphone and uses internet

Uses internet but does not own smartphone

Owns smartphone but does not use internet

Does not own smartphone or use internet

\section{Sociodemographic Factors Associated With Digital Access}

Specific characteristics distinguished smartphone owners and internet users from nonsmartphone owners and noninternet users (Table 1). Compared with smartphone owners and internet users, the respondents who reported not owning a smartphone or not using the internet were more likely to be older (both $P<.001$ ), less-educated (both $P<.001$ ), disabled (both $P<.001$ ), retired (both $P<.001$ ), publicly insured (both $P<.001$ ), and living in a nonmetropolitan area (both $P<.001$ ). The respondents who reported not owning a smartphone were also more likely to find 
it difficult or very difficult to get by on current income compared with smartphone owners $(P=.02)$.

\section{Digital Technology Use and Markers of Health Literacy}

Smartphone ownership and internet use demonstrated significant thematic associations with markers of health literacy (Table 2).

Table 2. Markers of health literacy and health access by smartphone ownership and internet use (N=2149). ${ }^{a}$

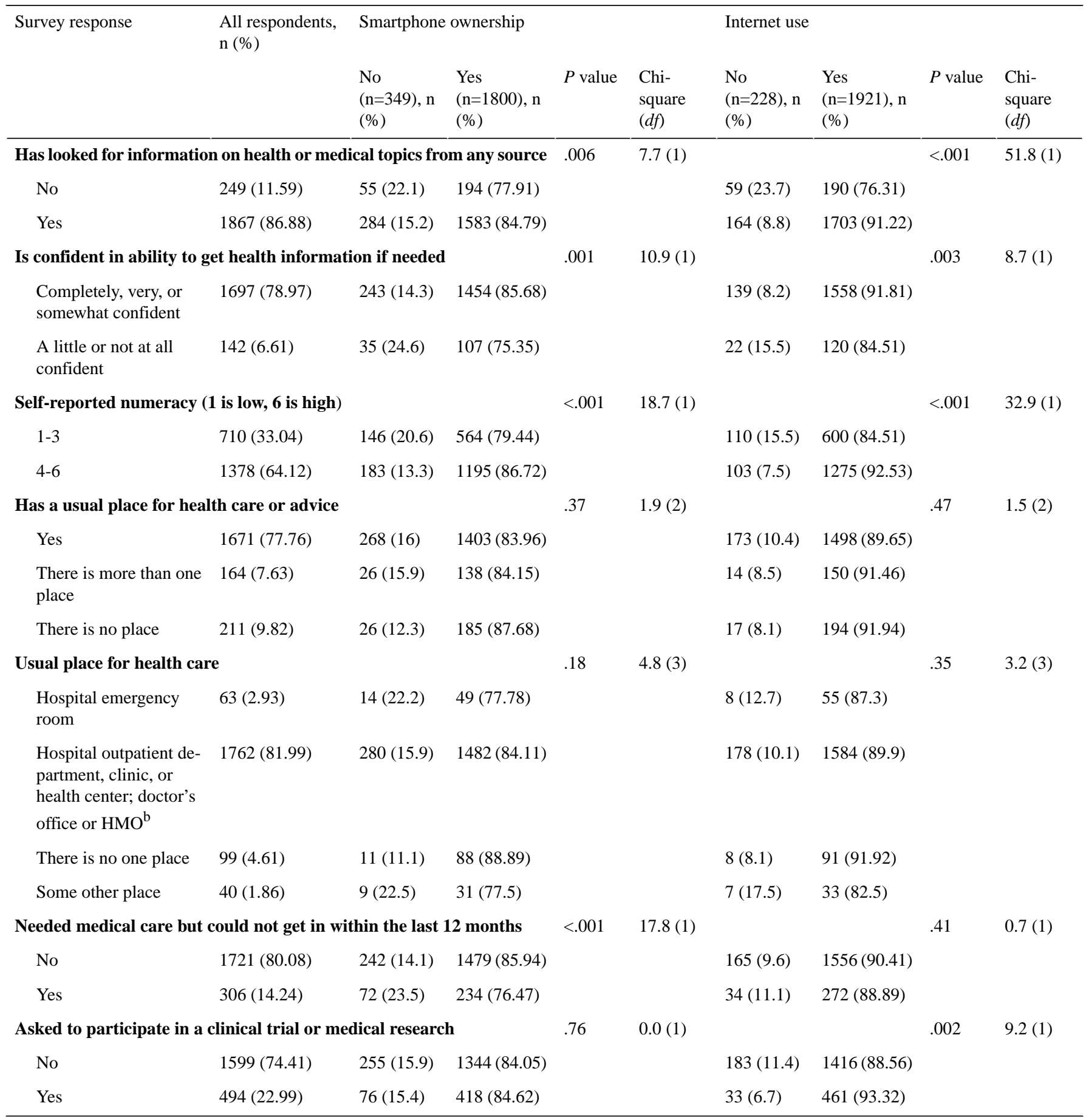

${ }^{\text {a }}$ Percentages may not add up to 100 owing to rounding or missing values.

${ }^{\mathrm{b}} \mathrm{HMO}$ : health maintenance organization.

On univariate analysis, both smartphone ownership and internet use were associated with higher self-reported numeracy (both $P<.001)$, confidence in obtaining health information if needed ( $P=.001$ and $P=.003$, respectively), and having looked for information on health topics from any source $(P=.006$ and $P<.001$, respectively).

In the adjusted analysis, smartphone ownership was associated with higher odds of having looked for health information (odds ratio [OR] 1.77, 95\% CI 1.14-2.76), when controlling for age, 
race and ethnicity, nativity, language spoken at home, income adequacy, occupational status, education level, insurance status, and rurality (Figure 2). Similarly, internet use was associated with higher odds of having looked for information on health topics (OR 3.81, 95\% CI 2.53-5.75), confidence in obtaining health information if needed (OR 1.83, 95\% CI 1.00-3.34), and self-reported numeracy (OR 1.47, 95\% CI 1.05-2.07) when controlling for age, occupational status, education level, insurance status, and rurality (Figure 2). Smartphone ownership models were adjusted for the following covariates: age, race and ethnicity, nativity, spoken language, income adequacy, occupational status, education level, insurance status, and rurality. Covariates were selected based on univariate analysis $(P<.10$ on univariate analysis). Internet use models were adjusted for the following covariates: age, occupational status, education level, insurance status, and rurality. Covariates were selected based on univariate analysis $(P<.10$ on univariate analysis).

Figure 2. Association of markers of health literacy and health access with smartphone ownership (top) and internet use (bottom). Separate models were used for each outcome listed on the left, with smartphone ownership or internet use included as a covariate.

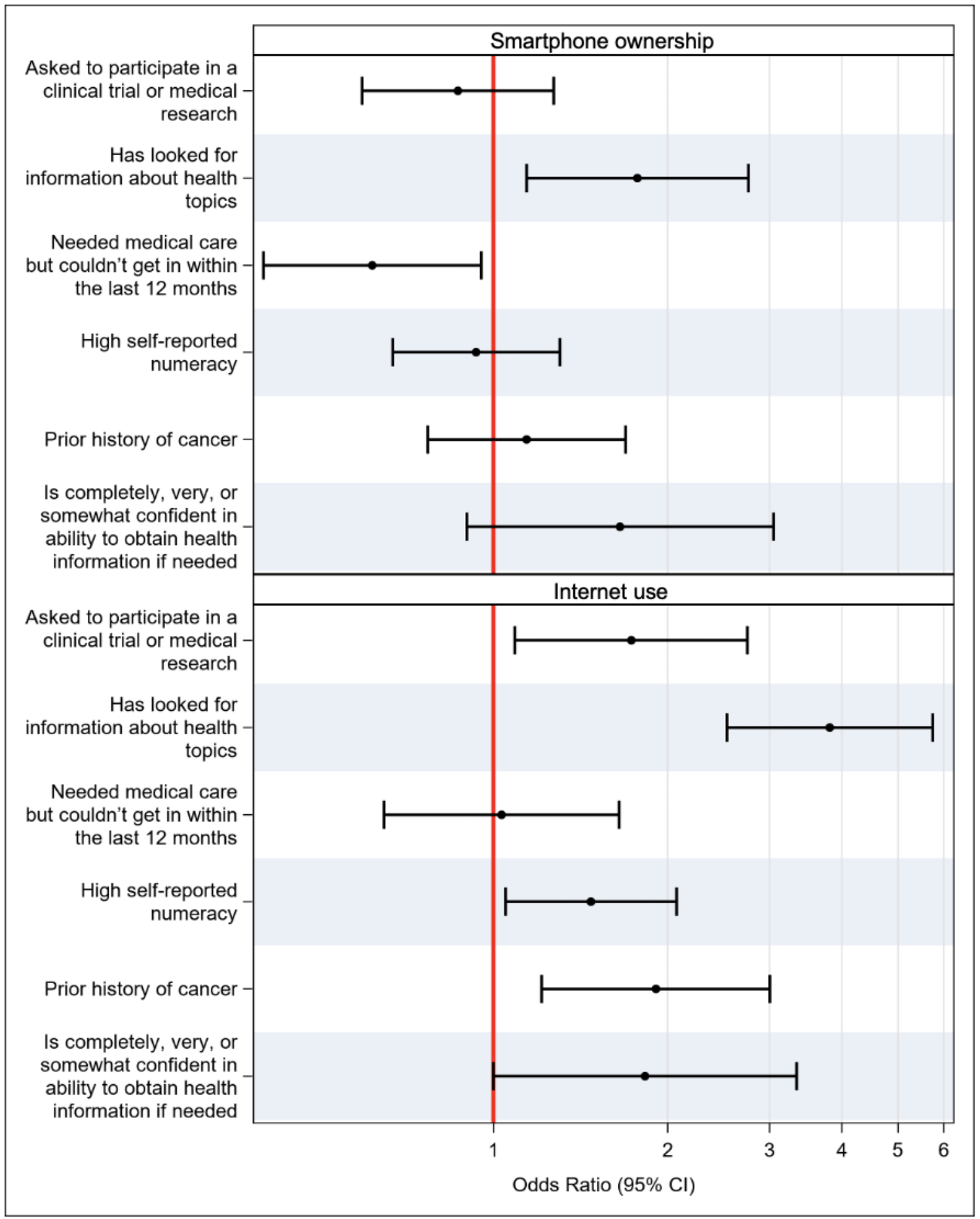

These differences were reflected in the sources of information that the respondents reported using to obtain health information
(Figures 3 and 4). Although most of the respondents did not use physicians as their most recent source of health information, 
the respondents without smartphones or internet access were more likely to have used a physician for this purpose $(116 / 349$, $33.2 \%$ of nonsmartphone owners vs $344 / 1800,19.11 \%$ of smartphone owners; $80 / 228,35.1 \%$ of noninternet users vs $380 / 1921,19.78 \%$ of internet users; both $P<.001)$. Similarly,

Figure 3. Source used most recently for health information by smartphone ownership.

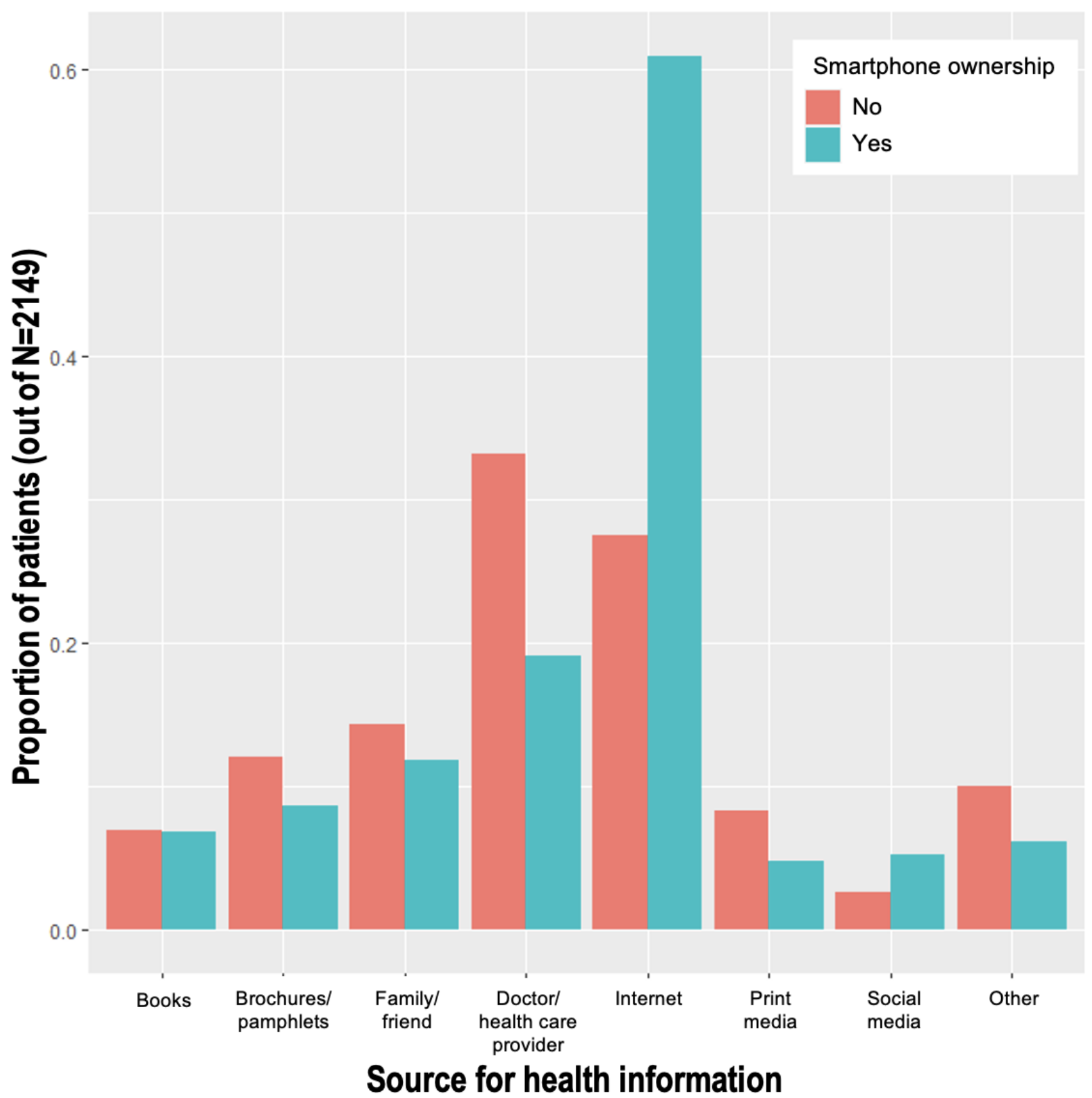


Figure 4. Source used most recently for health information by internet use.

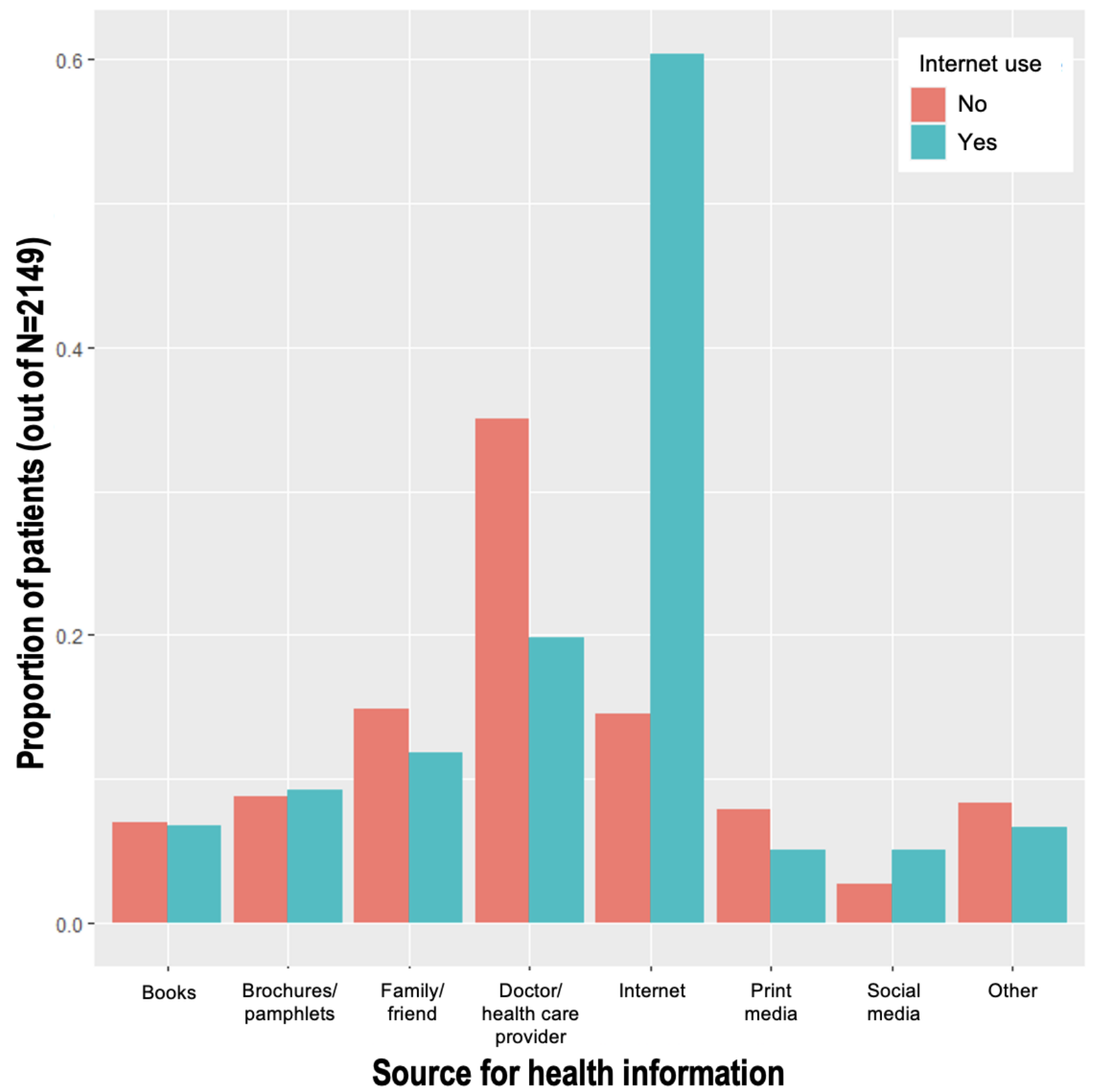

\section{Digital Technology Use and Health Access}

Smartphone ownership and internet use were also associated with markers of health care access (Table 2). Neither smartphone ownership nor internet use was significantly associated with having a usual place for health care or with using an outpatient office or clinic more frequently than the emergency room. However, smartphone owners were less likely than nonsmartphone owners to have been unable to obtain needed medical care within the last 12 months $(234 / 1800,13 \%$ vs 72/349, 20.6\%, respectively; $P<.001)$.

In adjusted analyses (Figure 2), controlled for age, race and ethnicity, nativity, language spoken at home, income adequacy, occupational status, education level, insurance status, and rurality, this relationship remained significant (OR 0.62, 95\% CI, 0.40-0.95). On univariate analysis, internet use was associated with users having been asked to participate in medical research $(73.7 \%, P=.002)$, and this relationship also remained significant in the adjusted analyses (OR $1.73,95 \%$ CI 1.09-2.75) when controlling for age, occupational status, education level, insurance status, and rurality (Figure 2).

\section{Digital Technology Use in Participants With a Personal History of Cancer}

The respondents who used the internet had higher odds of a personal history of cancer (OR 1.91, 95\% CI 1.21-3.01; Figure 2). In adjusted analyses, older age (OR 1.06, 95\% CI 1.05-1.07), disability (OR 4.12, 95\% CI 2.30-7.37), and retired status (OR $1.64,95 \%$ CI 1.08-2.49) were associated with an increased likelihood of a personal history of cancer. After stratifying the cohort by personal history of cancer, distinct relationships among smartphone ownership, internet use, and markers of health literacy and health access were observed. For participants 
with a personal history of cancer, smartphone owners had higher odds of being confident in their ability to obtain health information if needed (OR 5.63, 95\% CI 1.05-30.23) and lower odds of needing medical care but being unable to get it (OR $0.17,95 \%$ CI 0.06-0.47) compared with nonsmartphone owners, whereas these associations were not maintained among participants without a personal history of cancer (Figure 5). Similarly, among the participants with a history of cancer, internet users had higher odds of being confident in their ability to obtain health information if needed (OR 5.02, 95\% CI 1.12-22.55), whereas this association was not maintained among participants without a prior history of cancer. All models were adjusted for the following covariates: age, occupational status, education level, insurance status, and rurality. Covariates were selected based on univariate analysis $(P<.10$ on univariate analysis).

Figure 5. Association of smartphone ownership and internet use with markers of health literacy and health access in participants with (top) and without (bottom) a prior history of cancer. Separate models were used for each outcome listed on the left, with smartphone ownership or internet use included as a covariate.

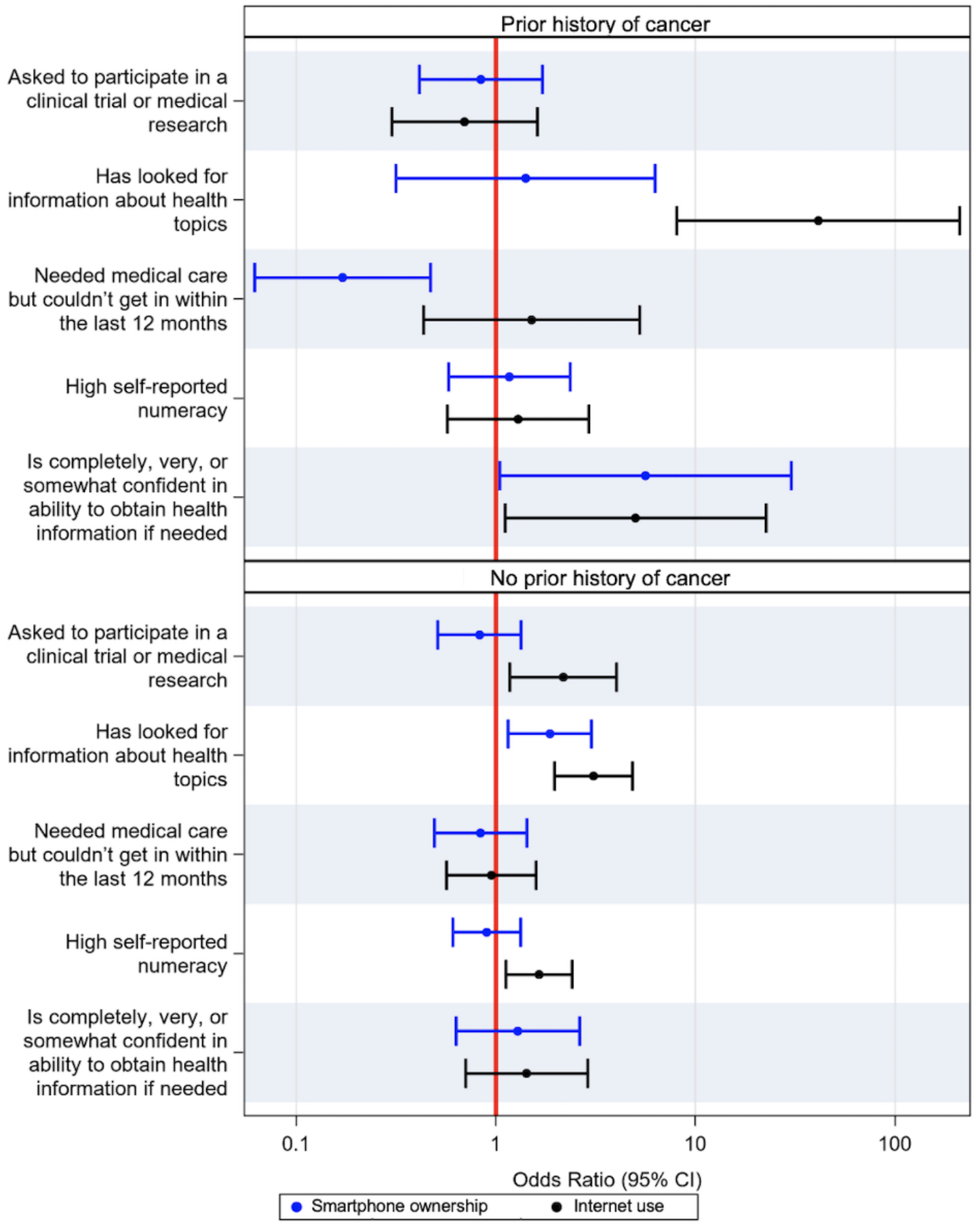




\section{Discussion}

\section{Principal Findings}

Ensuring access to telehealth is an increasingly important priority for the medical community because the COVID-19 pandemic has shifted a large proportion of care into the digital realm, and the convenient and inexpensive nature of the medium suggests that its popularity will persist long after the pandemic eases [47]. As smartphone ownership and internet access are essential modes of digital connectivity in a world that increasingly relies upon such modalities to facilitate health care, smartphone and internet access could have significant implications for health outcomes. Prior studies describing patterns of connectivity are nearly a decade old, suggesting a gap in current evidence [48-50].

The rates of internet use, mobile phone ownership, and smartphone ownership in our cohort were high, with $89.39 \%$ (1921/2149) of the respondents reporting internet use, $96.32 \%$ (2070/2149) reporting mobile phone access, and $83.76 \%$ (1800/2149) reporting smartphone ownership. These rates are higher than prior estimates [51], highlighting the trend described in multiple studies of continued growth in digital usership $[25,52,53]$. Despite this increasing use, we found that a digital divide persists across socioeconomic dimensions [23,24]. Nonsmartphone and noninternet users were more likely to be older, disabled or retired, less well-educated, on public insurance, and residents of rural areas. Participants without smartphones were also more likely to report finding it difficult or very difficult to get by on their current income. These socioeconomic disparities in digital access have important implications. Both smartphone ownership and internet use were consistently associated with markers of health literacy. Importantly, our findings are the first to demonstrate an additional association between smartphone use and health care access. Finally, these data suggest that having a major medical condition, such as cancer, may serve to reverse previously described relationships between sociodemographic characteristics and technology use.

Smartphone and internet use were consistently and thematically associated with markers of health-specific and overall literacy [54]. Participants without smartphone or internet access had lower self-reported numeracy and lower confidence in their ability to obtain health information when needed. They also reported being less likely to look for information on health topics, even when controlling for potential sociodemographic confounders. These findings support an evolving body of literature that demonstrates an integral connection between digital access and health literacy. In a survey of 1077 patients at community health centers and outpatient clinics, Bailey et al [31] found that patients with adequate health literacy were more likely to own a mobile phone or smartphone and to have internet access. Similarly, a cross-sectional study of 131 low-income adults by Jensen et al [32] found that those with low health literacy skills were less likely to use the internet and related technologies. Low health literacy has been consistently associated with increased rates of hospitalization, greater use of the emergency department, increased medication

nonadherence, decreased use of preventive services, and increased risk of mortality [55]. This body of data suggests that digital technology plays a key role in health outcomes.

Patient-provider communication may be an important mediator of the relationship between health literacy and health outcomes. In a survey of 823 patients presenting to an urban public hospital, Yin et al [56] found that patients with lower health literacy were more likely to rely on a doctor's knowledge to make medical decisions and less likely to rely on their own knowledge or beliefs. Similarly, the respondents in our study who did not own smartphones or use the internet were significantly more likely to use a health care provider as their most recent source of health information. Importantly, the survey study by Yin et al [56] found that patients with lower health literacy were less likely to feel like partners in shared decision-making with their providers. These findings point to the need for both provider-level and systemic changes to provide increased support for those who rely on face-to-face health communication to inform their care. In addition, these findings highlight the need for further research into provider reliance on patients' pre-existing medical knowledge or self-driven information seeking and how these behaviors may contribute to health disparities.

Our data are the first to demonstrate an association between smartphone ownership and disparities in access to care. Within our cohort, lack of smartphone ownership was significantly associated with being unable to obtain needed medical care, even when controlling for potential sociodemographic confounders, suggesting that characteristics associated with the use of digital technologies play a role in increasing health care access. Health literacy may be an important factor because prior studies have demonstrated an association between low health literacy and self-reported difficulty in accessing care [55,57]. However, health literacy is unlikely to be the only determinant because lack of internet use in our cohort was associated with lower markers of health literacy but was not significantly associated with being unable to obtain needed medical care. Taken together, these findings suggest that patients lacking smartphone access represent a unique subpopulation, distinct from those lacking internet access, and they may be the most vulnerable to the third digital divide [30] or the digital divide representing disparities in the impact of technology use on health outcomes. Indeed, even within our sample, nonsmartphone owners were distinct from noninternet users in key sociodemographic characteristics, including income adequacy. Future work should be directed toward identifying the unique barriers to care encountered by patients lacking smartphone access, including qualitative studies to assess patient experiences.

Finally, we found that a major health event such as a personal history of cancer may help overcome previously established sociodemographic patterns in digital technology use, with important implications for health outcomes. In our study, patients with a personal history of cancer were more likely to report internet use, despite being older than those without cancer, indicating that populations with historically low adoption of digital technologies, such as older patients [23], can be motivated to change their behavior when faced with a major 
illness. Importantly, our findings suggest that expanding digital access may also help to mitigate inequities in health care in this patient population. Among participants with a prior history of cancer, internet use and smartphone ownership were both significantly associated with confidence in being able to obtain needed health information. Smartphone use was also associated with lower odds of being unable to obtain needed medical care. In summary, the adoption of digital technologies in this patient population is associated with increased patient health activation, which in turn has been shown to have lasting benefits on health outcomes and health costs [58-60]. These findings demonstrate that engagement with the medical system in the form of a major illness can serve as a catalyst to overcome sociodemographic barriers to technology access, with the potential for improvement in long-term outcomes.

\section{Study Limitations}

Our study included limitations that should be acknowledged. First, this was a cross-sectional study, and as such no conclusions can be drawn regarding the causal relationships among the variables studied. Second, the goals of this study were mainly exploratory; therefore, no adjustments were made for multiple comparisons in the statistical analyses. Third, the study findings are derived from self-reported data, which are subject to recall bias and may not accurately reflect participant health literacy and health care use. Fourth, there was a relatively small sample size of participants with a prior history of cancer who did not engage in smartphone or internet use, limiting our goal of precisely estimating the relationship between technology use and markers of health literacy and access in this cohort. The impact of cancer history on the relationship among digital technology, health literacy, and health access may be best explored through an alternative study design, such as a case-control study. In addition, these survey data were collected in the second half of 2017, and although they capture more recent trends in digital connectivity than those available in currently published literature, patterns of digital technology use have continued to evolve since these data were collected. Finally, this study cohort represented a convenience sample in which study recruitment was purposefully targeted to allow the study of a diverse cohort that allows for in-depth analysis of previously understudied patient populations. Thus, there may have been unmeasured biases in the study population, and the extent to which our findings may be generalizable to the national or statewide population is unknown. Future work, including large-scale population-based studies and qualitative investigations, will help to elucidate the connections among digital technology use, health literacy, and health access that were explored here.

\section{Conclusions}

In conclusion, we found that access to digital technology has markedly increased across all social strata over the past decade in this diverse cohort of participants, leading to a more electronically connected society than ever before. This substantiates the claim that a broad digital infrastructure exists to support telemedicine as an increasingly important mode of patient engagement and health communication in the coming years. Nonetheless, a digital divide persists along sociodemographic and socioeconomic lines, with implications for both health literacy and access to care. Thus, dissemination of health technology must include measures to reach those with the most compromised health access. Importantly, our data support the idea that prolonged, meaningful contact with the health care system in the form of a major illness such as cancer has the potential to overcome sociodemographic trends in digital technology use and amplify the benefits these technologies confer. Future work should be directed toward the implementation of interventions to bridge the technology gap. In addition, more resources must be directed toward assisting vulnerable communities in engaging with applications of technology in the health sector because these applications hold promise in helping to mitigate health inequities and improve overall community health.

\section{Acknowledgments}

This work was supported by the Duke Cancer Institute through the National Institutes of Health grant P30CA014236 (principal investigator: Dr Michael B Kastan). The content of this manuscript is solely the responsibility of the authors and does not necessarily represent the official views of the National Institutes of Health.

\section{Conflicts of Interest}

SMT had a consultancy with Abbvie, Inc, on work related to bioequivalence. This relationship ended in January 2019 and was unrelated to the work. OMF is currently supported by the National Institutes of Health under award number 1 K08CA241390 (principal investigator: OMF).

\section{Multimedia Appendix 1}

Participant survey items.

[DOCX File, 92 KB-Multimedia Appendix 1]

\section{References}

1. Gadzinski AJ, Gore JL, Ellimoottil C, Odisho AY, Watts KL. Implementing telemedicine in response to the COVID-19 pandemic. J Urol 2020 Jul;204(1):14-16. [doi: 10.1097/ju.0000000000001033]

2. Fankhauser GT. Delivering high-quality vascular care by telehealth during the COVID-19 pandemic. J Vasc Surg 2020 Jul;72(1):6-7 [FREE Full text] [doi: 10.1016/j.jvs.2020.04.010] [Medline: 32289437] 
3. Ananthakrishnan AN, Singh S. The doctor will call you now! Telemedicine in the midst of a pandemic. Clin Gastroenterol Hepatol 2020 Jul;18(8):1688-1690 [FREE Full text] [doi: 10.1016/j.cgh.2020.04.031] [Medline: 32315781]

4. Oh H, Rizo C, Enkin M, Jadad A. What is eHealth (3): a systematic review of published definitions. J Med Internet Res 2005 Feb 24;7(1):e1 [FREE Full text] [doi: 10.2196/jmir.7.1.e1] [Medline: 15829471]

5. Neter E, Brainin E. eHealth literacy: extending the digital divide to the realm of health information. J Med Internet Res 2012 Jan 27;14(1):e19 [FREE Full text] [doi: 10.2196/jmir.1619] [Medline: 22357448]

6. Irizarry T, Dabbs AD, Curran CR. Patient portals and patient engagement: a state of the science review. J Med Internet Res 2015 Jun 23;17(6):e148 [FREE Full text] [doi: 10.2196/jmir.4255] [Medline: 26104044]

7. Claridy MD, Hudson MM, Caplan L, Mitby PA, Leisenring W, Smith SA, et al. Patterns of internet-based health information seeking in adult survivors of childhood cancer. Pediatr Blood Cancer 2018 May 19;65(5):e26954 [FREE Full text] [doi: 10.1002/pbc.26954] [Medline: 29350454]

8. Cocco AM, Zordan R, Taylor DM, Weiland TJ, Dilley SJ, Kant J, et al. Dr Google in the ED: searching for online health information by adult emergency department patients. Med J Aust 2018 Oct 15;209(8):342-347. [doi: 10.5694/mja17.00889] [Medline: $\underline{30107763}$ ]

9. Corrales DM, Wells AE, Breitkopf CR, Pena G, Kaplan AL, King LS, et al. Internet use by gynecologic oncology patients and its relationship with anxiety. J Health Commun 2018 Feb 23;23(3):299-305. [doi: 10.1080/10810730.2018.1442529] [Medline: 29474124]

10. George G, Iwuanyanwu E, Buford A, Piha-Paul SA, Subbiah V, Fu S, et al. Cancer-related internet use and its association with patient decision making and trust in physicians among patients in an early drug development clinic: a questionnaire-based cross-sectional observational study. J Med Internet Res 2019 Mar 14;21(3):e10348 [FREE Full text] [doi: 10.2196/10348] [Medline: $\underline{30869638}$ ]

11. Loeb S, Sengupta S, Butaney M, Macaluso JN, Czarniecki SW, Robbins R, et al. Dissemination of misinformative and biased information about prostate cancer on Youtube. Eur Urol 2019 Apr;75(4):564-567. [doi: 10.1016/j.eururo.2018.10.056] [Medline: 30502104]

12. Ranard BL, Werner RM, Antanavicius T, Schwartz HA, Smith RJ, Meisel ZF, et al. Yelp reviews of hospital care can supplement and inform traditional surveys of the patient experience of care. Health Aff (Millwood) 2016 Apr;35(4):697-705 [FREE Full text] [doi: 10.1377/hlthaff.2015.1030] [Medline: 27044971]

13. Shneyderman Y, Rutten LJ, Arheart KL, Byrne MM, Kornfeld J, Schwartz SJ. Health information seeking and cancer screening adherence rates. J Cancer Educ 2016 Mar 27;31(1):75-83. [doi: 10.1007/s13187-015-0791-6] [Medline: 25619195]

14. Hudson DB, Campbell-Grossman C, Hanna KM, Fial AV. Health-related mobile phone-based programs and health-care utilization by mothers of infants: an integrative review. J Technol Behav Sci 2019 Dec 20;5(2):121-128. [doi: 10.1007/s41347-019-00119-5]

15. Bendtsen M, Müssener U, Linderoth C, Thomas K. A mobile health intervention for mental health promotion among university students: randomized controlled trial. JMIR Mhealth Uhealth 2020 Mar 20;8(3):e17208 [FREE Full text] [doi: 10.2196/17208] [Medline: 32196462]

16. Martin C, Gilmore L, Apolzan J, Myers C, Thomas D, Redman L. Smartloss: a personalized mobile health intervention for weight management and health promotion. JMIR Mhealth Uhealth 2016 Mar 16;4(1):e18 [FREE Full text] [doi: 10.2196/mhealth.5027] [Medline: 26983937]

17. Barsky J, Hunter R, McAllister C, Yeates K, Campbell N, Liu P, et al. Analysis of the implementation, user perspectives, and feedback from a mobile health intervention for individuals living with hypertension (DREAM-GLOBAL): mixed methods study. JMIR Mhealth Uhealth 2019 Dec 09;7(12):e12639 [FREE Full text] [doi: 10.2196/12639] [Medline: $\underline{31815678]}$

18. Report to congress: e-health and telemedicine. U.S. Department of Health and Human Services. 2016. URL: https://aspe. hhs.gov/system/files/pdf/206751/TelemedicineE-HealthReport.pdf [accessed 2021-05-15]

19. Tuckson RV, Edmunds M, Hodgkins ML. Telehealth. N Engl J Med 2017 Oct 19;377(16):1585-1592. [doi: 10.1056/nejmsr1503323]

20. Doolittle GC, Spaulding AO. Providing access to oncology care for rural patients via telemedicine. J Oncol Pract 2006 Sep 01;2(5):228-230. [doi: 10.1200/jop.2.5.228]

21. Uscher-Pines L, Mehrotra A. Analysis of Teladoc use seems to indicate expanded access to care for patients without prior connection to a provider. Health Aff (Millwood) 2014 Feb;33(2):258-264. [doi: 10.1377/hlthaff.2013.0989] [Medline: 24493769]

22. van Dijk JA. Digital divide research, achievements and shortcomings. Poetics 2006 Aug;34(4-5):221-235. [doi: 10.1016/j.poetic.2006.05.004]

23. Ernsting C, Dombrowski SU, Oedekoven M, Sullivan JL, Kanzler M, Kuhlmey A, et al. Using smartphones and health apps to change and manage health behaviors: a population-based survey. J Med Internet Res 2017 Apr 05;19(4):e101 [FREE Full text] [doi: 10.2196/jmir.6838] [Medline: 28381394]

24. Liu Z, Ng M, Gunasekeran DV, Li H, Ponampalam K, Ponampalam R. Mobile technology: usage and perspective of patients and caregivers presenting to a tertiary care emergency department. World J Emerg Med 2020;11(1):5-11 [FREE Full text] [doi: 10.5847/wjem.j.1920-8642.2020.01.001] [Medline: $\underline{\text { 31892997] }}$ 
25. Anderson M. Mobile technology and home broadband 2019. Pew Research Center. 2019. URL: https://www.pewresearch.org/ internet/2019/06/13/mobile-technology-and-home-broadband-2019/ [accessed 2020-04-27]

26. Hillyer GC, Schmitt KM, Lizardo M, Reyes A, Bazan M, Alvarez MC, et al. Electronic Communication Channel Use and Health Information Source Preferences Among Latinos in Northern Manhattan. J Community Health 2017 Apr 21;42(2):349-357 [FREE Full text] [doi: 10.1007/s10900-016-0261-z] [Medline: 27655586]

27. Smith A. Older Adults and Technology Use. Pew Research Center. 2014. URL: https://www.pewresearch.org/internet/ 2014/04/03/older-adults-and-technology-use/ [accessed 2021-05-15]

28. Gonzales A. The contemporary US digital divide: from initial access to technology maintenance. Inf Commun Soc 2015 Jun 02;19(2):234-248. [doi: 10.1080/1369118x.2015.1050438]

29. van Deursen AJ, van Dijk JA. The first-level digital divide shifts from inequalities in physical access to inequalities in material access. New Media Soc 2019 Feb 07;21(2):354-375 [FREE Full text] [doi: 10.1177/1461444818797082] [Medline: $\underline{30886536}$

30. Neter E, Brainin E, Baron-Epel O. The third digital divide in the health domain: is internet use for health purposes associated with health benefits? In: Hale TM, Chou WY, Cotten SR, editors. eHealth: Current Evidence, Promises, Perils, and Future Directions. Bingley, United Kingdom: Emerald Publishing Limited; 2018:1-320.

31. Bailey SC, O'Conor R, Bojarski EA, Mullen R, Patzer RE, Vicencio D, et al. Literacy disparities in patient access and health-related use of internet and mobile technologies. Health Expect 2015 Dec 02;18(6):3079-3087 [FREE Full text] [doi: 10.1111/hex.12294] [Medline: 25363660]

32. Jensen JD, King AJ, Davis LA, Guntzviller LM. Utilization of internet technology by low-income adults: the role of health literacy, health numeracy, and computer assistance. J Aging Health 2010 Sep 21;22(6):804-826. [doi: 10.1177/0898264310366161] [Medline: 20495159]

33. Manganello J, Gerstner G, Pergolino K, Graham Y, Falisi A, Strogatz D. The relationship of health literacy with use of digital technology for health information: implications for public health practice. J Public Health Manag Pract 2017;23(4):380-387. [doi: 10.1097/PHH.0000000000000366] [Medline: 26672402]

34. Mackert M, Mabry-Flynn A, Champlin S, Donovan EE, Pounders K. Health literacy and health information technology adoption: the potential for a new digital divide. J Med Internet Res 2016 Oct 04;18(10):e264 [FREE Full text] [doi: 10.2196/jmir.6349] [Medline: 27702738]

35. Estacio EV, Whittle R, Protheroe J. The digital divide: examining socio-demographic factors associated with health literacy, access and use of internet to seek health information. J Health Psychol 2019 Oct 01;24(12):1668-1675. [doi: 10.1177/1359105317695429] [Medline: 28810415]

36. Scheerder A, van Deursen A, van Dijk J. Determinants of internet skills, uses and outcomes. A systematic review of the second- and third-level digital divide. Telemat Inform 2017 Dec;34(8):1607-1624. [doi: 10.1016/j.tele.2017.07.007]

37. Neter E, Brainin E. Association between health literacy, ehealth literacy, and health outcomes among patients with long-term conditions. Eur Psychol 2019 Jan;24(1):68-81. [doi: 10.1027/1016-9040/a000350]

38. Ramsetty A, Adams C. Impact of the digital divide in the age of COVID-19. J Am Med Inform Assoc 2020 Jul 01;27(7):1147-1148 [FREE Full text] [doi: 10.1093/jamia/ocaa078] [Medline: 32343813]

39. Osborn R, Squires D, Doty MM, Sarnak DO, Schneider EC. In new survey of eleven countries, US adults still struggle with access to and affordability of health care. Health Aff (Millwood) 2016 Dec 01;35(12):2327-2336. [doi: 10.1377/hlthaff.2016.1088] [Medline: 27856648]

40. Mattsson S, Olsson EM, Johansson B, Carlsson M. Health-related internet use in people with cancer: results from a cross-sectional study in two outpatient clinics in Sweden. J Med Internet Res 2017 May 15;19(5):e163 [FREE Full text] [doi: 10.2196/jmir.6830] [Medline: 28506959]

41. Ginossar T. Predictors of online cancer prevention information seeking among patients and caregivers across the digital divide: a cross-sectional, correlational study. JMIR Cancer 2016 Mar 09;2(1):e2 [FREE Full text] [doi: 10.2196/cancer.5108] [Medline: 28410177]

42. Tai C, Hiatt R. The population burden of cancer: research driven by the catchment area of a cancer center. Epidemiol Rev 2017 Jan 01;39(1):108-122. [doi: 10.1093/epirev/mxx001] [Medline: 28472310]

43. Barrett N, Ingraham K, Bethea K, Hwa-Lin P, Chirinos M, Fish LJ, et al. Project PLACE: enhancing community and academic partnerships to describe and address health disparities. Adv Cancer Res 2020;146:167-188 [FREE Full text] [doi: 10.1016/bs.acr.2020.01.009] [Medline: 32241388]

44. Gage-Bouchard EA, Rawl SM. Standardizing measurement of social and behavioral dimensions of cancer prevention and control to enhance outreach and engagement in NCI-designated cancer centers. Cancer Epidemiol Biomarkers Prev 2019 Jan 22;28(3):431-434. [doi: 10.1158/1055-9965.epi-18-0794]

45. Rural-urban continuum codes. Economic Research Service, U.S. DEPARTMENT OF AGRICULTURE. URL: https://www. ers.usda.gov/data-products/rural-urban-continuum-codes/ [accessed 2020-03-10]

46. Butler M, Beale C. Rural-urban continuum codes for metro and nonmetro counties, 1993. United States Department of Agriculture, Economic Research Service 1994:278774. [doi: 10.22004/ag.econ.278774]

47. Hollander JE, Carr BG. Virtually perfect? Telemedicine for Covid-19. N Engl J Med 2020 Apr 30;382(18):1679-1681. [doi: $\underline{10.1056 / \text { nejmp2003539] }}$ 
48. Roblin DW, Houston TK, Allison JJ, Joski PJ, Becker ER. Disparities in use of a personal health record in a managed care organization. J Am Med Inform Assoc 2009 Sep 01;16(5):683-689. [doi: 10.1197/jamia.m3169]

49. Ancker JS, Barrón Y, Rockoff ML, Hauser D, Pichardo M, Szerencsy A, et al. Use of an electronic patient portal among disadvantaged populations. J Gen Intern Med 2011 Oct 7;26(10):1117-1123 [FREE Full text] [doi: 10.1007/s11606-011-1749-y] [Medline: 21647748]

50. Goel MS, Brown TL, Williams A, Hasnain-Wynia R, Thompson JA, Baker DW. Disparities in enrollment and use of an electronic patient portal. J Gen Intern Med 2011 Oct 3;26(10):1112-1116 [FREE Full text] [doi: 10.1007/s11606-011-1728-3] [Medline: 21538166]

51. Poushter J. Smartphone ownership and internet usage continues to climb in emerging economies. Pew Research Center. 2016. URL: https://www.pewresearch.org/global/2016/02/22/ smartphone-ownership-and-internet-usage-continues-to-climb-in-emerging-economies/ [accessed 2021-05-15]

52. Smith A. Smartphone ownership-2013 update. Pew Research Center. 2013. URL: https://www.pewresearch.org/internet/ wp-content/uploads/sites/9/media/Files/Reports/2013/PIP_Smartphone_adoption_2013_PDF.pdf [accessed 2021-05-15]

53. Torous J, Chan SR, Tan SY, Behrens J, Mathew I, Conrad EJ, et al. Patient smartphone ownership and interest in mobile apps to monitor symptoms of mental health conditions: a survey in four geographically distinct psychiatric clinics. JMIR Ment Health 2014 Dec 23;1(1):e5 [FREE Full text] [doi: 10.2196/mental.4004] [Medline: 26543905]

54. Kiechle ES, Bailey SC, Hedlund LA, Viera AJ, Sheridan SL. Different measures, different outcomes? A systematic review of performance-based versus self-reported measures of health literacy and numeracy. J Gen Intern Med 2015 Oct 28;30(10):1538-1546 [FREE Full text] [doi: 10.1007/s11606-015-3288-4] [Medline: 25917656]

55. Berkman ND, Sheridan SL, Donahue KE, Halpern DJ, Crotty K. Low health literacy and health outcomes: an updated systematic review. Ann Intern Med 2011 Jul 19;155(2):97-107. [doi: 10.7326/0003-4819-155-2-201107190-00005] [Medline: 21768583]

56. Yin HS, Dreyer BP, Vivar KL, MacFarland S, van Schaick L, Mendelsohn AL. Perceived barriers to care and attitudes towards shared decision-making among low socioeconomic status parents: role of health literacy. Acad Pediatr 2012 Mar;12(2):117-124 [FREE Full text] [doi: 10.1016/j.acap.2012.01.001] [Medline: 22321814]

57. Levy H, Janke A. Health literacy and access to care. J Health Commun 2016 Apr 04;21 Suppl 1(sup1):43-50 [FREE Full text] [doi: 10.1080/10810730.2015.1131776] [Medline: 27043757]

58. Greene J, Hibbard JH. Why does patient activation matter? An examination of the relationships between patient activation and health-related outcomes. J Gen Intern Med 2012 May 30;27(5):520-526 [FREE Full text] [doi:

10.1007/s11606-011-1931-2] [Medline: 22127797]

59. Greene J, Hibbard JH, Sacks R, Overton V, Parrotta CD. When patient activation levels change, health outcomes and costs change, too. Health Aff (Millwood) 2015 Mar;34(3):431-437. [doi: 10.1377/hlthaff.2014.0452] [Medline: 25732493]

60. Hibbard JH, Greene J, Shi Y, Mittler J, Scanlon D. Taking the long view: how well do patient activation scores predict outcomes four years later? Med Care Res Rev 2015 Jun 24;72(3):324-337. [doi: 10.1177/1077558715573871] [Medline: $\underline{25716663]}$

\section{Abbreviations \\ RUCC: Rural-Urban Continuum Code \\ OR: odds ratio}

Edited by R Kukafka; submitted 11.10.20; peer-reviewed by E Neter, S Speedie, A Hidki, JR Bautista; comments to author 10.01.21;
revised version received 08.03.21; accepted 25.04.21; published 09.06.21
Please cite as:
Oshima SM, Tait SD, Thomas SM, Fayanju OM, Ingraham K, Barrett NJ, Hwang ES
Association of Smartphone Ownership and Internet Use With Markers of Health Literacy and Access: Cross-sectional Survey Study
of Perspectives From Project PLACE (Population Level Approaches to Cancer Elimination)
J Med Internet Res 2021;23(6):e24947
URL: https://www.jmir.org/2021/6/e24947
doi: $10.2196 / 24947$
PMID:

(CSachiko M Oshima, Sarah D Tait, Samantha M Thomas, Oluwadamilola M Fayanju, Kearston Ingraham, Nadine J Barrett, E Shelley Hwang. Originally published in the Journal of Medical Internet Research (https://www.jmir.org), 09.06.2021. This is an open-access article distributed under the terms of the Creative Commons Attribution License (https://creativecommons.org/licenses/by/4.0/), which permits unrestricted use, distribution, and reproduction in any medium, 
provided the original work, first published in the Journal of Medical Internet Research, is properly cited. The complete bibliographic information, a link to the original publication on https://www.jmir.org/, as well as this copyright and license information must be included. 